\title{
DOES EMOTIONAL HEALTH INFLUENCE SUSCEPTIBILITY TO THE PHYSIOLOGIC EFFECTS OF AIR POLLUTION ON ADULTS?
}

\author{
S. CAKMAK ${ }^{1}$, R.E. DALES ${ }^{1,2} \&$ C.V. BLANCO ${ }^{3}$ \\ ${ }^{1}$ Population Studies Division, Health Canada, Canada \\ ${ }^{2}$ University of Ottawa, Canada \\ ${ }^{3}$ IPSUSS, Chile
}

\begin{abstract}
Depression has been linked to an increased susceptibility to physical illness. Our objective is to determine if emotional health modifies the effect of air pollution on pulmonary and cardiovascular physiology. This cross-sectional study was based on data collected on 5,604 subjects between 2007 and 2009 during the Canadian Health Measures Survey. Subjects were assigned the air pollution values obtained from the National Air Pollution monitor closest to the subject's home. We tested the associations between air pollution and lung function, heart rate and blood pressure for adults whose ages were greater than 20 when the survey was conducted. Results were stratified by a self-reported happiness scale (HS). Among those who were less happy ('others'), an interquartile increase in fine particulate air pollution was associated with a $2.86 \%(95 \% \mathrm{CI} 0.41,5.31)$ increase in systolic blood pressure, a $1.70 \%$ (95\% CI 0.07, 3.33) decrease in forced vital capacity (FVC), and a $1.59 \%(95 \%$ CI $0.09,3.08)$ decrease in the FEV1/FVC ratio (ratio of percent predicted 1-second forced expiratory volume (FEV1) to FVC). Significant adverse effects were observed for six 'others' air pollution - physiology associations. In 'happy' group, none of the associations were significant. In the Canadian population, the degree of happiness may modify the vulnerability to the adverse health effects of air pollution. Keywords: air pollution, blood pressure, emotional health, epidemiology, lung.
\end{abstract}

\section{INTRODUCTION}

Identifying subgroups of the population exceptionally vulnerable to the effects of air pollution has been a research priority for many years [1]. Evidence has emerged that the socially disadvantaged, very young, very old and those with chronic cardiopulmonary disease may bear a higher proportion of the burden of illness from air pollution than the general population [2].

Emotional illness may confer an increased vulnerability to physical illness [3-6]. A review of eleven cohort studies concluded that the presence of depression increased the future relative risk of a myocardial infarction by over 50\% [3]. A cohort study of company employees in Japan observed an increased risk of developing diabetes among those with pre-existing depression [4]. A study from China of patients with chronic obstructive lung disease, reported an increased risk of exacerbations among those with evidence of depression [5].

The primary objective of the present study was to determine if emotional health influences susceptibility to the adverse effects of air pollution. We used data from the Canadian Health Measures Survey (CHMS) to test the associations between air pollution and lung function, 
and between heart rate and blood pressure. We then determined if the observed effect size was less for those with more favourable indicators of emotional health.

\section{RESEARCH METHODS}

\subsection{Study population}

The CHMS collected cross-sectional health data based on questionnaires and physiologic measures on over 5,000 participants between March 2007 and February 2009. The target population was Canadians between the ages of 6 and 79 years old among the approximately 27 million people as identified by the 2001 National census. Stratified sampling was done by the following age groups $(6-11,12-19,20-39,40-59$, and 60-79 years). Details of the sampling strategy have been previously described [7], and will herein be summarised [8]. The country was divided into five regions (British Columbia, the Prairies, Ontario, Quebec, and The Atlantic provinces) and 257 potential sampling sites of at least 1,000 people living within $100 \mathrm{~km}$ of each other. Fifteen sites were selected for the study by probability sampling based on population size of the potential sites. Within each site, households were stratified by age group, with at least one subject of the desired age living in the household. Simple random sampling was done to choose approximately 600 dwellings per site for the study [9]. For the purpose of creating a representative population sample, survey weights were assigned after the responding sample was determined to adjust for non-response and non-random sample selection. The bootstrap method was used to estimate standard errors and confidence intervals [10]. In our analysis we only included adults whose ages were greater than 20 when the survey was conducted.

\subsection{Questionnaire}

The questionnaire was administered by a trained interviewer according to a standardized protocol clinic questionnaire [11]. Happiness was indicated by the question: 'Would you describe yourself as being usually: ... happy and interested in life ... somewhat happy ... somewhat unhappy ... unhappy with little interest in life ... so unhappy that life is not worthwhile?'

\subsection{Air pollution and weather}

Meteorological data were supplied by the National Climate Data and Information Archive [12]. Air pollution data were provided by The Canadian National Air Pollution Surveillance (NAPS) network which has approximately 300 monitoring stations in about 200 communities [13]. For analysis, we used the maximum 8-hr average for $\mathrm{O}_{3}$, and the 24-hr means for $\mathrm{PM}_{2.5}$, and $\mathrm{NO}_{2}$, temperature, humidity and barometric pressure measured on the day of the test for each of the 15 study sites.

\subsection{Physiologic measures}

\subsubsection{Blood pressure}

The measurement techniques were guided by Campbell et al. [14]. After 5 minutes seated in a quiet environment, six measurements were taken, at 1 minute intervals, on the right arm 
using an automated blood pressure device (BpTRUTM BP-300) with a cuff 40\%-50\% of the arm circumference. The mean of the last five measures were used for analysis [15].

\subsubsection{Lung function}

Trained personnel adhered to the guidelines of the American Thoracic Society/European Respiratory Society Task Force quality criteria report for test performance using a KoKo Spirometer $^{\mathrm{TM}}$ (Ferraris CardioRespiratory, Pulmonary Data Services, Inc. Louiseville, CO 80027 USA) [16]. Calibration with a 3 L syringe was done prior to each testing session. Variables used in analysis were the largest 1 -second forced expiratory volume $\left(\mathrm{FEV}_{1}\right)$ and forced vital capacity (FVC) obtained by a minimum of three and a maximum of eight trials [15].

\section{STATISTICAL ANALYSIS}

Generalized linear mixed models were used to test the associations between air pollution and health outcomes. The testing site was treated as random effects to control for the influence of site on health outcomes. Lung function was expressed as a percentage of predicted based on age, height, and gender using previously developed prediction equations [17]. To determine if emotional health modifies the effect of air pollution on physiology, we calculated the percentage change in physiologic measure for an interquartile range (IQR) increase in air pollutant by categories of emotional health. Covariates tested for inclusion included age, gender, body mass index, ethnicity (Caucasian versus other), greatest household education, household income, current active smoking (daily, occasionally, not at all), household exposure to passive smoking (daily or almost daily, other), alcohol consumption (none, other), mean daily temperature and relative humidity. The final model included age, gender, greatest household education, household income, active smoking and temperature. Relative humidity and barometric pressure were not significant. Data management and regression modeling were completed in SAS, v9.1 (Cary, NC, USA).

\section{RESULTS}

A total of 2,720 participants $(78.40 \%)$ reported that they were happy (Table 1$)$.

Those who were happy compared to others, were approximately $2 \%$ more likely to be female, $7 \%$ most likely to have at least a high school education, and $1.8 \%$ less likely to smoke. Heart rate was $1 \mathrm{bpm}$ lower among those who were happy vs. other. Lung function was significantly better for happy group. However, Blood pressure measurements were similar between two groups. Happy group has approximately 20,000 more yearly household income compared to others. There were significant differences between happy and other group, in exposure to measured $\mathrm{NO}_{2}$ (Table 2). However, there was no evidence that exposure to ambient concentrations of $\mathrm{PM}_{2.5}$ and ozone was significantly greater among other group.

Effect modification by emotional health was investigated by presenting the association between air pollution and physiologic measures stratified by happy vs. other (Table 3 ).

For six physiologic variables, a significant effect of air pollution was observed for less happy subjects (Other) but not for happy subjects. Expressed as a percent change in physiology for an IQR increase in air pollutant, results were as follows: For $\mathrm{NO}_{2}$, there was a $0.85 \%(95 \%$ CI $0.02,1.68)$ increase in systolic blood pressure. For Ozone, there was a $1.27 \%(95 \%$ CI $0.04,2.49)$ increase in diastolic blood pressure, and $2.06 \%$ (95\% CI 0.28 , $3.84)$ decrease in the FEV1/FVC. For PM2.5, there was a $2.86 \%$ (95\% CI 0.41, 5.31) 
Table 1: Sociodemographic and physiologic characteristics of the study population. Values are means ( $95 \%$ confidence intervals) or number (percentages).

\begin{tabular}{|c|c|c|c|}
\hline \multicolumn{4}{|c|}{ Self-reported mood disorder } \\
\hline & $\begin{array}{c}\text { Happy } \\
(\mathrm{n}=\mathbf{2 , 7 2 0}) \\
\end{array}$ & $\begin{array}{c}\text { Other } \\
(\mathrm{n}=749)\end{array}$ & $\begin{array}{c}\text { Difference } \\
(95 \% \mathrm{CI})\end{array}$ \\
\hline \multicolumn{4}{|l|}{$\begin{array}{l}\text { Sociodemographic } \\
\text { characteristics }\end{array}$} \\
\hline Age & $49.06(48.47,49.65)$ & $47.84(46.7,48.97)$ & $1.22(-0.06,2.49)$ \\
\hline Sex, \% male & $46.95(46.45,47.48)$ & $49.00(48.28,47.48)$ & $2.05(1.8,2.30)$ \\
\hline \multicolumn{2}{|c|}{$\begin{array}{l}\text { Highest household ed- } 82.10(81.70,82.50) \\
\text { ucation, \% completed } \\
\text { high school }\end{array}$} & $74.97(74.85,75.09)$ & $7.13(6.80,7.46)$ \\
\hline Heart rate (bpm) & $67.3(66.91,67.69)$ & $68.48(67.73,69.22)$ & $-1.18(-2.02,-0.33)$ \\
\hline $\begin{array}{l}\text { Systolic pressure } \\
(\mathrm{mmHg})\end{array}$ & $\begin{array}{l}114.17(113.57, \\
114.78)\end{array}$ & $\begin{array}{l}114.83(113.62, \\
116.03)\end{array}$ & $-0.65(-1.97,0.66)$ \\
\hline $\begin{array}{l}\text { Diastolic pressure } \\
(\mathrm{mmHg})\end{array}$ & $71.89(71.54,72.24)$ & $72.67(71.98,73.35)$ & $-0.78(-1.54,-0.02)$ \\
\hline FEV1, \% predicted & $95.15(94.59,95.71)$ & $93.56(92.39,94.72)$ & $1.59(0.36,2.83)$ \\
\hline FVC, $\%$ predicted & $98.52(98.01,99.02)$ & $97.27(96.25,98.3)$ & $1.24(0.13,2.35)$ \\
\hline FEV1/FVC & $96.22(95.9,96.54)$ & $95.77(95.07,96.46)$ & $0.45(-0.25,1.16)$ \\
\hline
\end{tabular}

increase in systolic blood pressure, a $1.70 \%$ (95\% CI 0.07, 3.33) decrease in FVC, and a $1.59 \%$ (95\% CI 0.09, 3.08) decrease in FEV1/FVC.

There was no effect of ozone, $\mathrm{NO}_{2}$ or $\mathrm{PM}_{2.5}$ among those who were happy.

\section{DISCUSSION}

\subsection{Summary}

Emotional health, indicated by a simple question, appears to be a risk indicator which may indicate an increased susceptibility to the adverse physiologic effects of air pollution. It is important to note that air pollution levels were well within Canadian and American guidelines, suggesting that susceptible subgroups may not be fully protected by current standards.

5.2 Importance of determining if mood disorders increases susceptibility to adverse effects of air pollution

The existence of susceptible subgroups should be identified and taken into account when interpreting studies on the population health effects of air pollution.

Setting air pollution guidelines based on observed effects in the general population may be insufficient to protect especially vulnerable subgroups. Also the most susceptible may derive the most benefit from reduction in air pollution. Based on modelling, the expected health 
Table 2: Ambient air pollution concentrations stratified by reported mood disorder. Values are means and $95 \%$ confidence intervals.

\begin{tabular}{lllc}
\hline \multicolumn{3}{c}{ Self-reported mood disorder } \\
\hline & \multicolumn{1}{c}{ Happy } & \multicolumn{1}{c}{ Other } & \multicolumn{1}{c}{ Difference } \\
\cline { 2 - 4 } Air pollutant & \multicolumn{1}{c}{$(\mathbf{n}=\mathbf{2 , 7 2 0})$} & $(\mathbf{n}=\mathbf{7 4 9})$ & \multicolumn{1}{c}{$\mathbf{( 9 5 \% ~ C I )}$} \\
\hline $\mathrm{NO}_{2,}(\mathrm{IQR}=11.48 \mathrm{ppb})$ & 12.05 & $13.01(12.36,13.66)$ & $-0.96(-1.67,-0.24)$ \\
& $(11.72,12.38)$ & & \\
$\mathrm{O}_{3}(\mathrm{IQR}=17.38 \mathrm{ppb})$ & 30.08 & 29.71 & $0.37(-0.69,1.44)$ \\
$\mathrm{PM}_{2.5}\left(\mathrm{IQR}=3.96 \mu \mathrm{g} / \mathrm{m}^{3}\right)$ & $(29.59,30.57)$ & $(28.73,30.68)$ & \\
\hline
\end{tabular}

Table 3: The percent change in heart rate, blood pressure, and lung function for an IQR increase in air pollutant concentration stratified by happy vs. other. Results are adjusted for age, gender, education, income, and active smoking.

\begin{tabular}{|c|c|c|c|c|}
\hline $\begin{array}{l}\text { Physiologic } \\
\text { outcome }\end{array}$ & Happiness & $\mathrm{NO}_{2}(\mathrm{IQR}=11.63)$ & $\mathrm{O}_{3}(\mathrm{IQR}=17.38)$ & $\mathrm{PM}_{2.5}(\mathrm{IQR}=4.17)$ \\
\hline \multirow{2}{*}{$\begin{array}{l}\text { Heart rate } \\
(\mathrm{bpm})\end{array}$} & Happy & $-0.4(-1.01,0.21)$ & $0.75(-1.26,2.76)$ & $0.05(-1.1,1.92)$ \\
\hline & Other & $-0.07(-1.32,1.19)$ & $0.04(-1.62,1.7)$ & $-0.28(-1.34,0.79)$ \\
\hline \multirow{2}{*}{$\begin{array}{l}\text { Systolic } \\
\text { pressure } \\
(\mathrm{mmHg})\end{array}$} & Happy & $-0.3(-1.95,1.34)$ & $1.63(-1.62,4.88)$ & $0.05(-1.54,1.63)$ \\
\hline & Other & $0.85(0.02,1.68)$ & $-0.28(-2.73,2.16)$ & $2.86(0.41,5.31)$ \\
\hline \multirow{2}{*}{$\begin{array}{l}\text { Diastolic } \\
\text { pressure } \\
(\mathrm{mmHg})\end{array}$} & Happy & $-0.38(-0.91,0.16)$ & $0.65(-1.16,2.45)$ & $0.54(-0.83,1.91)$ \\
\hline & Other & $0.14(-0.97,1.24)$ & $1.27(0.04,2.49)$ & $0.25(-0.78,1.28)$ \\
\hline \multirow{2}{*}{$\begin{array}{l}\mathrm{FEV}_{1} \\
\text { (\%predicted) }\end{array}$} & Happy & $0.4(-0.47,1.26)$ & $-1.81(-5.83,2.21)$ & $1.39(-1.82,4.59)$ \\
\hline & Other & $1.37(-0.63,3.38)$ & $-1.07(-4,1.86)$ & $0.8(-1.13,2.73)$ \\
\hline \multirow{2}{*}{$\begin{array}{l}\text { FVC } \\
\text { (\%predicted) }\end{array}$} & Happy & $0.37(-0.41,1.15)$ & $-0.11(-3.17,2.95)$ & $-0.22(-2.67,2.23)$ \\
\hline & Other & $0.7(-1.05,2.45)$ & $1.03(-1.46,3.52)$ & $-1.7(-3.33,-0.07)$ \\
\hline \multirow{2}{*}{$\begin{array}{l}\text { FEV1/FVC } \\
(\%)\end{array}$} & Happy & $0.03(-0.47,0.54)$ & $-1.6(-4.13,0.93)$ & $-0.33(-1.49,0.84)$ \\
\hline & Other & $0.94(-0.26,2.14)$ & $-2.06(-3.84,-0.28)$ & $-1.59(-3.08,-0.09)$ \\
\hline
\end{tabular}

*Bold font indicates the $95 \%$ confidence intervals exclude zero.

benefits of reducing emissions from fossil-fuel power plants, Levy et al. [19] reported disproportionate mortality reductions among African Americans, those with less than a high-school education, and those with diabetes. The impact of a mood disorder on susceptibility was not addressed.

Identifying the especially vulnerable would be a first step in focusing prevention strategies. For example, the Air Quality Health Index communicates to the public both a summary of the 
air quality and preventative advice which differs between those with and without an elevated risk due to chronic lung or heart disease and the general population [20].

If a self-reported mood disorder identifies a subgroup at higher risk of adverse health effects from air pollution than the general population, obtaining this simple measure may help explain variability between studies with different proportions of reported emotional disorders. In developed countries, $1 \%$ to $6 \%$ of emotional illnesses were associated with severe disability. In developing countries disability associated with emotional illness was reported to be greater than for most physical illnesses [21].

\subsection{Reasons why mood disorders may increase susceptibility to air pollution}

There is evidence that emotional illness may increase vulnerability to physical illness. Possible reasons may include: Unfavourable self-care behaviours (not seeking care, not adhering to treatment, smoking), lack of social and financial support, increased symptom reporting unrelated to presence or severity of physical illness, and a mood-induced proinflammatory state.

\subsubsection{The association between depression and illness}

Depression has been associated with an increased future risk of morbidity and mortality from medical disorders. A systematic review of 11 cohort studies published between 1966 and 2000 estimated a relative risk of 1.64 (95\% CI 1.29, 2.08) for the association between depression and myocardial infarction or cardiac mortality [3]. A recent study suggested an interactive effect of depression and ethnicity on the association between blood pressure and lead. Among those who were depressed, Blacks had a larger increase in blood pressure for a doubling of blood lead than did whites. This differential effect was not seen among those who were not depressed [6].

\subsubsection{Lack of financial and social support}

A questionnaire-based survey was carried out in 1,082 people from 35 countries suffering from major depressive disorder [22]. Depression was found to adversely affect employment and social functioning, and a fear of discrimination may impede accessing care. In our study sample, we did not find that household income or educations was significantly lower among those with reported mood disorders, and the effect of air pollution persisted despite adjusting for both income and education. This suggests that lower social status is not the explanation for the observed effect modification.

\subsubsection{Non-adherence to treatment}

Based on a systematic review of the literature between 1968 and 1998, DiMatteo et al. [23] calculated an odds ratio of 3.03 (95\% confidence interval, 1.96-4.89) between depression and treatment noncompliance. Non-adherence to medications for lung disease or blood pressure may be one explanation for why people with depression appear susceptible to illness, and perhaps the effect of air pollution. We did not have compliance measures to test this hypothesis.

\subsubsection{Aggravation of systemic inflammation}

Exposure to air pollution may cause oxidative stress, the production of reactive oxygen species, and inflammation. This may be one mechanism explaining observed association between 
air pollution and cardiovascular morbidity. There is also some evidence of an association between depression and pro-inflammatory cytokines although the direction of the relation is uncertain. Kiecolt-Glaser and Glaser [24] present an argument that psychological stress and depression increase IL-6, a marker of inflammation, and decrease cellular and humoral immunity. Among 3,024 subjects between 70 and 79 years of age, those who scored higher on a standardized depression scale also had significantly higher levels of IL-6, TNF, and CRP. Results were adjusted for any of the following covariates significantly different between the two groups at $\mathrm{p}<0.2$ : age, sex, BMI, diabetes, heart or lung disease, cigarette and alcohol consumption and medications [25]. Caregivers for family members with dementia are considered to be in a chronically stressful situation. Over a 6-year period, interleukin-6 increased fourfold in this group compared to a control group who were not caregivers [26]. Caregivers also had higher levels of loneliness and stress as measured by standardized questionnaires. Stress-related increases in pro-inflammatory cytokines by emotional distress and by exposure to air pollution may theoretically have an interactive or synergistic effect accounting for our observations.

\subsection{Strengths and limitations of the study}

Using physiologic measures of lung function avoided the possibility of a self-reporting bias whereby, for a given level of physical illness, depression may increase or decrease the likelihood of symptom reporting independent of the severity or the underlying illness. Cross-sectional studies have an inherent weakness in that they take a snapshot in time, in this case the day the subject was studied. A longitudinal study would be required to determine if the observed effects are from relatively acute or chronic exposure to air pollutants. However, on average, subjects with exposures to greater concentrations of air pollution on the day of the study will also be chronically exposed to greater concentrations on a chronic basis than subjects who are less exposed on the day of the study.

\section{CONCLUSION}

Self-reported depression appears to influence susceptibility to the adverse physiologic effects of air pollution. We recommend further studies, including longitudinal studies, and testing whether or not mood disorders modify the effect of air pollution on other physical health outcomes.

\section{ACKNOWLEDGEMENTS}

The authors thank Statistics Canada for providing the survey data.

\section{REFERENCES}

[1] Committee on Research Priorities for Airborne Particulate Matter, National Research Council, "Executive Summary". Research Priorities for Airborne Particulate Matter: I. Immediate Priorities and a Long-Range Research Portfolio, The National Academies Press: Washington, DC, 1998.

[2] Sacks, J.D., Stanek, L.W., Luben, T.J., Johns, D.O., Buckley, B.J., Brown, J.S, \& Ross, M., Particulate matter-induced health effects: who is susceptible? Environmental Health Perspectives, 119(4), pp. 446-454, 2011. http://dx.doi.org/10.1289/ehp.1002255 
[3] Rugulies, R., Depression as a predictor for coronary heart disease. A review and metaanalysis. American Journal of Preventive Medicine, 23(1), pp. 51-56, 2002. http://dx.doi.org/10.1016/S0749-3797(02)00439-7

[4] Kawakami, N., Takatsuka, H., Shimizu, H. \& Ishibashi, H., Depressive symptoms and occurrence of type II diabetes among Japanese men. Diabetes Care, 22(7), pp. 10711076, 1999. http://dx.doi.org/10.2337/diacare.22.7.1071

[5] Xu, W., Collet, J.P., Shapiro, S., Lin, Y., Yang, T., Platt, R.W., Wang, C. \& Bourbeau, J., Independent effect of depression and anxiety on chronic obstructive pulmonary disease exacerbations and hospitalizations. American Journal of Respiratory and Critical Care Medicine, 178(9), pp. 913-920, 2008.

http://dx.doi.org/10.1164/rccm.200804-619OC

[6] Hicken, M.T., Gee, G.C., Connell, C., Snow, R.C., Morenoff, J. \& Hu, H., Black-white blood pressure disparities: depressive symptoms and differential vulnerability to blood lead. Environmental Health Perspectives, 121(2), pp. 205-209, 2012. http://dx.doi.org/10.1289/ehp.1104517

[7] StatCan, available at http://www23.statcan.gc.ca/imdb-bmdi/pub/document/5071_D2_ T1_V1-eng.htm

[8] Dales, R.E, Cakmak, S., Leech, J. \& Liu, L., The association between personal care products and lung function. Annals of Epidemiology, 23(2), pp. 49-53, 2013. http://dx.doi.org/10.1016/j.annepidem.2012.11.006

[9] Wilkins, K., Campbell, N.R.C., Joffres, M.R., McAlister, F.A., Nichol, M., Quach, S., Johansen, H.L. \& Tremblay, M.S., Blood pressure in Canadian adults. Health Reports, Statistics Canada Catalogue no. 82-003-XPE, 21(1), pp. 37-46, 2001, available at http://www.statcan.gc.ca/pub/82-003-x/2010001/article/11118-eng.pdf

[10] Rao, J.N.K., Wu, C.F.J. \& Yue, K., Some recent work on re-sampling methods for complex surveys. Survey Methodology. Statistics Canada Catalogue, 18(2), pp. 209-217, 1992.

[11] EnvCanada, available at http://www.climate.weatheroffice.gc.ca

[12] EnvCanada, available at http://www.ec.gc.ca/rnspa-naps/Default.asp?lang= En\&n=5C0D33CF-1

[13] Carelton, available at http://www.library.carleton.ca/sites/default/files/find/data/surveys/pdf_files/chms-c1-07-09-que-hhld.pdf

[14] Campbell, N.R, Joffres, M.R, McKay, D.W., Hypertension surveillance in Canada: minimum standards for assessing blood pressure in surveys. Canadian Journal of Public Health, 96(3), pp. 217-220, 2005.

[15] Cakmak, S., Dales, R., Leech, J. \& Liu, L., The influence of air pollution on cardiovascular and pulmonary function and exercise capacity: Canadian health measures survey. Environmental Research, 111(8), pp. 1309-1312, 2011. http://dx.doi.org/10.1016/j.envres.2011.09.016

[16] Miller, M.R., Hankinson, J., Brusasco, V., Burgos, F., Casaburi, R., Coates, A., Crapo, R., Enright, P., van der Grinten, C.P.M., Gustafsson, P., Jensen, R., Johnson, D.C., MacIntyre, N., McKay, R., Navajas, D., Pedersen, O.F., Pellegrino, R., Viegi, G. \& Wanger, J., Standardization of spirometry. European Respiratory Journal, 126(2), pp. 319-338, 2005.

http://dx.doi.org/10.1183/09031936.05.00034805 
[17] Hankinson, J.L., Odencrantz, J.R., Fedan, K.B., Spirometric reference values from a sample of the general U.S. Population. American Journal of Respiratory and Critical Care Medicine, 159(1), pp. 179-187, 1999.

http://dx.doi.org/10.1164/ajrccm.159.1.9712108

[18] EPA, available at http://www.epa.gov/air/criteria.html, http://www.hc-sc.gc.ca/ewhsemt/air/out-ext/reg-eng.php

[19] Levy, J.I., Greco, S.L. \& Spengler, J.D., The importance of population susceptibility for air pollution risk assessment: a case study of power plants near Washington, DC.

Environ Health Perspectives, 110(12), pp. 1253-1260, 2002. http://dx.doi.org/10.1289/ehp.021101253

[20] Stieb, D.M., Burnett, R.T., Smith-Doiron, M., Brion, O., Shin, H.H. \& Economou, V., A New multipollutant, no-threshold air quality health index based on short-term associations observed in daily time-series analyses. Journal of the Air \& Waste Management Association, 58(3), pp. 435-450, 2008.

http://dx.doi.org/10.3155/1047-3289.58.3.435

[21] Kessler, R.C., Aguilar-Gaxiola, S., Alonso, J., Chatterji, S., Lee, S., Ormel, J., Ustun, T.B. \& Wang, P.S., The global burden of emotional disorders: an update from the WHO World Emotional Health (WMH) surveys. Epidemiologia Psichiatria Sociale, 18(1), pp. 23-33, 2009. http://dx.doi.org/10.1017/S1121189X00001421

[22] Lasalvia, A., Zoppei, S., Van Bortel, T., Bonetto, C., Cristofalo, D., Wahlbeck, K., Bacle, S.V., Audenhove, C.V., Weeghel, J.V., Reneses, B., Germanavicius, A., Economou, M., Lanfredi, M., Ando, S., Sartorius, N., Lopez-Ibor, J.J. \& Thornicroft, G., Global pattern of experienced and anticipated discrimination reported by people with major depressive disorder: a cross-sectional survey. Lancet, 381(9860), pp. 55-62, 2013. http://dx.doi.org/10.1016/S0140-6736(12)61379-8

[23] DiMatteo, M.R., Leppe, H.S. \& Croghan, T.W., Depression is a risk factor for noncompliance with medical treatment: meta-analysis of the effects of anxiety and depression on patient adherence. Archives of Internal Medicine, 160(14), pp. 2101-2107, 2000. http://dx.doi.org/10.1001/archinte.160.14.2101

[24] Kiecolt-Glaser, J.K. \& Glaser, R., Depression and immune function. Central pathways to morbidity and mortality. Journal of Psychosomatic Research, 53(4), pp. 873-876, 2002.

http://dx.doi.org/10.1016/S0022-3999(02)00309-4

[25] Penninx, B.W., Kritchevsky, S.B., Yaffe, K., Newman, A.B., Simonsick, E.M. \& Rubin, S., Inflammatory markers and depressed mood in older persons: Results from the health, aging and body composition study. Biological Psychiatry, 54(5), pp. 566-572, 2003.

http://dx.doi.org/10.1016/S0006-3223(02)01811-5

[26] Kiecolt-Glaser, J.K., Preacher, K.J., MacCallum, R.C., Atkinson, C., Malarkey, W.B. \& Glaser, R., Chronic stress and age-related increases in the proinflammatory cytokine IL-6. Proceeding of the National Academy of Sciences USA, 100(15), pp. 9090-9095, 2003. http://dx.doi.org/10.1073/pnas.1531903100 